\title{
Nestin as a novel therapeutic target for pancreatic cancer via tumor angiogenesis
}

\author{
KAZUYA YAMAHATSU $^{1,2}$, YOKO MATSUDA ${ }^{1}$, TOSHIYUKI ISHIWATA ${ }^{1}$, EIJI UCHIDA $^{2}$ and ZENYA NAITO ${ }^{1}$ \\ ${ }^{1}$ Departments of Pathology and Integrative Oncological Pathology, Nippon Medical School, 1-1-5 Sendagi, \\ Bunkyo-ku, Tokyo 113-8602; ${ }^{2}$ Surgery for Organ and Biological Regulation, Graduate School of Medicine, \\ Nippon Medical School, 1-1-5 Sendagi, Bunkyo-ku, Tokyo 113-8603, Japan
}

Received October 25, 2011; Accepted December 20, 2011

DOI: $10.3892 /$ ijo.2012.1333

\begin{abstract}
The class VI intermediate filament protein, nestin is reported to be a progenitor cell marker in various tissues. In the present study, we analyzed the expression and roles of nestin in angiogenesis of pancreatic ductal adenocarcinomas, and determined whether nestin is a potential target for inhibiting tumor angiogenesis using a gene silencing strategy. Nestin expression was detected only in small vessels, whereas CD34, CD31 and factor VIII were also expressed in large-sized blood vessels in PDAC. The number of nestin-positive vessels was approximately $20 \%$ the number of CD34-positive vessels, and the average dimension of nestin-positive vessels was approximately $75 \%$ that of CD34-positive vessels. The PCNA labeling indices of nestin-positive vessels were higher than those of CD34-positive vessels and nestin-negative vessels. Reducing nestin expression by use of siRNA targeting nestin transcripts inhibited growth of the vascular endothelial cell lines, but there was no difference in cell motility. In xenograft models, administration of siRNA targeting mouse-nestin suppressed subcutaneous human pancreatic cancer cell growth in nude mice. In conclusion, nestin was expressed in small proliferating blood vessels in pancreatic cancer tissues and may be a useful marker of angiogenesis in pancreatic ductal adenocarcinoma tissues. Furthermore, nestin is a potential novel therapeutic target in pancreatic cancers to inhibit tumor angiogenesis.
\end{abstract}

\section{Introduction}

Pancreatic ductal adenocarcinoma (PDAC) is an aggressive malignancy with an overall 5-year survival rate of less than 5\% (1). PDAC patients that undergo resection frequently experience disease recurrence with a high incidence of lymph node or liver metastases and peritoneal dissemination, resulting in a

Correspondence to: Dr Toshiyuki Ishiwata, Departments of Pathology and Integrative Oncological Pathology, Nippon Medical School, 1-1-5 Sendagi, Bunkyo-ku, Tokyo 113-8602, Japan

E-mail: ishiwata@nms.ac.jp

Key words: nestin, pancreatic ductal adenocarcinoma, tumor angiogenesis, siRNA poor clinical prognosis (2). Tumor angiogenesis is an important factor in the proliferation, invasion, metastasis, and drug sensitivity of PDAC $(3,4)$. A possible explanation of this metastatic mechanism is that the increased number of tumor vessels increases the chance that tumor cells enter into the circulation. Newly formed tumor vessels or capillaries have weak, leaky basement membranes; thus, tumor cells can penetrate these more easily than they can mature vessels (5). Furthermore, increased numbers of vessels in tumors supply oxygen and nutrients to the tumor cells. The degree of tumor angiogenesis is associated with clinical outcome, and angiogenic properties correlate with tumor aggressiveness $(3,4)$. Angiogenesis in malignant tumors, measured by microvessel density (MVD), reportedly correlates with prognosis in breast (6), ovarian (7), esophageal (8), gastric (9), colorectal (10), prostate (11), lung (12), and malignant melanomas (13), but it has been controversial in PDAC. The hot-spot method and the lumen method using endothelial specific antigens are reportedly useful for analyzing tumor angiogenesis $(14,15)$. CD34, CD31, and factor VIII are commonly used as endothelial cell markers in tumor vessels. However, these markers identify not only newly-formed small vessels, but also pre-existing large blood vessels (16).

Nestin is a class VI intermediate filament protein originally found in neuroepithelial stem cells and neural cells (17). Nestin expression was up-regulated in progenitor cells in various tissues such as muscle, testis, teeth, heart, and pancreas. This upregulation was usually followed by decreased expression when the cells reached their differentiated states (18-20). Furthermore, increased nestin expression has been reported in various tumor cells, including central nervous system tumors (21), PDACs (22), gastrointestinal stromal tumors (23), prostate cancers (24), breast cancers (25), malignant melanomas (26), dermatofibrosarcoma protuberances (27) and thyroid tumors (28).

Recently, nestin expression in endothelial cells that accompanied the process of angiogenesis has been reported (29-33). The nestin expression was specific to proliferative endothelium, and nestin regulates the proliferation of HUVEC cells. We reported that nestin-positive vessels show higher proliferation rates than CD34-positive vessels in colorectal carcinoma (30) and nestin is strongly expressed in proliferating endothelial cells in a rat model of acute pancreatitis (34). Furthermore, nestin was reported to be a marker of proliferating endothelial cells in brain tumor tissues (35) and prostate cancer (36). 
These reports indicate that nestin may be a useful marker of newly-formed blood vessels in tumor tissues. Regarding PDAC, studies focusing on angiogenesis have gradually increased in recent years. However, detailed expression patterns and the roles of nestin in vascular endothelial cells of PDAC have not been reported. In this study, we compared the number, dimension and proliferative ability of nestin- and CD34-positive blood vessels in PDAC tissues to determine the usefulness of nestin as a marker of angiogenesis in this disease. We determined the effect of small interfering RNA (siRNA) targeting nestin in vitro and in vivo to clarify whether nestin could be a novel therapeutic target of tumor angiogenesis in PDAC.

\section{Materials and methods}

Materials. Histofine Simple Stain Max-PO (M), (R), and (G) kits and mouse monoclonal anti-human CD34 antibody were from Nichirei (Tokyo, Japan); mouse monoclonal anti-human nestin antibody was from R\&D Systems, Inc. (Minneapolis, $\mathrm{MN}$ ); mouse monoclonal anti-human PCNA antibody, rabbit polyclonal anti-human factor VIII antibody, mouse monoclonal anti-human D2-40 antibody and mouse monoclonal anti-alpha smooth muscle ( $\alpha$-SMA) antibody were from DakoCytomation (Carpinteria, CA); goat polyclonal anti-human LYVE-1 antibody, rabbit polyclonal anti-human VEGFR3 antibody, and goat polyclonal anti-mouse nestin antibody were from Santa Cruz Biotech (Santa Cruz, CA); mouse monoclonal anti-human CD31 antibody was from AbD Serotec (Oxford, UK); new silane II slide glass and a malinol mounting medium were from Mutoh Chemical Co. (Tokyo, Japan); TransIT-si-QUEST was from Mirus Bio LLC (Madison, WI); siRNA targeting mouse nestin, silencer select negative control no. 1, High-Capacity cDNA Reverse Transcription kits, and TaqMan Gene Expression Assays for nestin and 18S rRNA were from Applied Biosystems, Inc. (Carlsbad, CA); 35-mm poly-L-lysine-coated glass-bottomed dish and 35-mm multi-well glass-bottomed dish were from Matsunami Glass Ind., Ltd. (Osaka, Japan); Alexa 488-labeled goat anti-rabbit IgG antibody and Alexa 488-labeled donkey anti-mouse IgG antibody from Invitrogen Corp. (Carlsbad, CA); Vectashield H-1200 containing 4',6-diamidino-2-phenylindole$2 \mathrm{HCl}$ (DAPI) were from Vector Lab., Inc. (Burlingame, CA); Cascade Biologics Medium 200 and Cascade Biologics LSGS from BD Bioscience (Franklin Lakes, NJ); WST-8 cell counting kit was purchased from Wako Pure Chemical Industries (Osaka, Japan) and AteloGene was purchased from Koken Co., Ltd. (Tokyo, Japan). All other chemicals and reagents were purchased from Sigma Chemical Co. (St. Louis, MO, USA).

Human PDAC tissues. Forty-five PDAC patients who participated in this study were from among those receiving treatment at Nippon Medical School Hospital (Tokyo, Japan) from 1995 to 2008. The clinicopathological features of the patients are summarized in Table I. The clinicopathological stage was determined according to the TNM classification system of the International Union Against Cancer. Non-cancer PDAC tissue was obtained from the heterotopic spleen of the pancreas $(\mathrm{N}=1)$ and normal pancreatic tissue was obtained from Novagen (Darmstadt, Germany). Formalin-fixed and paraffin-embedded specimens were prepared for hematoxylin and eosin staining, Elastica van Gieson (EVG) staining, and immunohistochemistry. This study was carried out in accordance with the principles embodied in the Declaration of Helsinki, 2008, and informed consent was obtained from each patient for the usage of pancreatic tissues.

Immunohistochemistry. The 3.5- $\mu \mathrm{m}$, paraffin-embedded serial tissue sections were subjected to immunostaining for nestin, CD34, CD31, factor VIII, LYVE-1, D2-40, VEGFR3, $\alpha$-SMA, S-100, and PCNA using the Histofine Simple Stain Max-PO kits as previously reported $(22,30)$. After deparaffinization, endogenous peroxidase activity was blocked by incubation with $0.3 \%$ hydrogen peroxide in methanol for $30 \mathrm{~min}$. For CD31, VEGFR3, and PCNA immunostaining, sections were pretreated in an autoclave at $121^{\circ} \mathrm{C}$ for $15 \mathrm{~min}$ in $10 \mathrm{mM}$ citrate buffer (pH 6.0). Then the tissue sections were incubated with the appropriate antibody (1:100 dilution for the anti-human nestin antibody, 1:150 dilution for the anti-human CD34 antibody, 1:50 dilution for the anti-human CD31 antibody, 1:1000 dilution for the anti-human factor VIII antibody, 1:100 dilution for the anti-human LYVE-1 antibody, 1:100 dilution for the anti-human D2-40 antibody, 1:200 dilution for the anti-human VEGFR3 antibody, 1:100 dilution for the anti-human $\alpha$-SMA antibody, 1:100 dilution for the anti-human S-100 antibody or 1:200 dilution for the anti-PCNA antibody) in phosphate-buffered saline (PBS) containing $1 \%$ bovine serum albumin (BSA), overnight at $4^{\circ} \mathrm{C}$. Bound antibodies were detected with the Histofine Simple Stain Max-PO reagents using diaminobenzidine tetrahydrochloride (DAB) as the substrate, and the sections were counterstained with Mayer's hematoxylin. Negative control experiments were performed by omitting the primary antibodies.

Microvessel counting. Microvessels were assessed according to the international consensus report (37). In short, slides immunostained with anti-human nestin or anti-human CD34 antibodies were scanned at magnification x100 to identify the areas with the highest number of vessels. Each image was captured using an Olympus DP71 Digital Camera system (Olympus Optical, Tokyo, Japan) attached to an Olympus AX80 microscope at magnification $\mathrm{x} 200$. Each magnification $\mathrm{x} 200$ area was $0.64 \mathrm{~mm}^{2}$. Counts were performed on five separate fields, and a lumen with stained epithelial cells was counted as one vessel by WinROOF version 6.1.3 (Mitani Corp., Tokyo, Japan) (38). The number and dimension of microvessels were counted, and the median of the microvessel counts was used for analyses.

Pancreatic cancer and vascular endothelial cell lines. PANC-1 and KLM-1, pancreatic cancer cell lines, were obtained from the Cell Resource Center for Biomedical Research Institute of Development, Aging and Cancer Tohoku University (Sendai, Japan). TKD2, a mouse immortalized vascular endothelial cell line, was obtained from Health Science Research Resources Bank (Osaka, Japan). Human umbilical vein endothelial cell (HUVEC)-2, derived from single donor and cryopreserved at the end of passage level 1 was obtained from BD Bioscience (Franklin Lakes, NJ). PANC-1 and KLM-1cells were grown in RPMI 1640 medium containing 10\% fetal bovine serum (FBS) at $37^{\circ} \mathrm{C}$ under a humidified $5 \% \mathrm{CO}_{2}$ atmosphere. TKD2 cells were grown in DMEM medium containing $10 \% \mathrm{FBS}$ at $33^{\circ} \mathrm{C}$ under a humidified $5 \% \mathrm{CO}_{2}$ atmosphere according to supplier's protocol. HUVEC-2 cells were grown in Cascade Biologics' Medium 200 supplemented with Cascade Biologics LSGS at $37^{\circ} \mathrm{C}$. 
Table I. Correlation of clinicopathological features and the number of nestin- or CD34-positive vessels.

\begin{tabular}{|c|c|c|c|c|}
\hline \multirow[b]{2}{*}{ Variables } & \multicolumn{2}{|c|}{ No. of nestin(+) vessels } & \multicolumn{2}{|c|}{ No. of CD34(+) vessels } \\
\hline & Low $(<20.0)$ & High $(\geq 20.0)$ & Low $(<99.0)$ & $\operatorname{High}(\geq 99.0)$ \\
\hline \multicolumn{5}{|l|}{ Mean age $64.62 \pm 10.85$} \\
\hline \multicolumn{5}{|l|}{ Sex } \\
\hline Men & 10 & 17 & 12 & 15 \\
\hline Women & 9 & 9 & 10 & 8 \\
\hline \multicolumn{5}{|l|}{ Histology } \\
\hline Well differentiated & 9 & 15 & 12 & 12 \\
\hline Moderately/poorly differentiated & 10 & 11 & 10 & 11 \\
\hline \multicolumn{5}{|l|}{ Stage } \\
\hline $1-3$ & 4 & 8 & 6 & 6 \\
\hline 4 & 15 & 18 & 16 & 17 \\
\hline \multicolumn{5}{|l|}{ Vascular invasion } \\
\hline Positive & 10 & 9 & 8 & 11 \\
\hline Negative & 9 & 17 & 14 & 12 \\
\hline \multicolumn{5}{|l|}{ Lymphatic invasion } \\
\hline Positive & 15 & 25 & 18 & 22 \\
\hline Negative & 4 & 1 & 4 & 1 \\
\hline \multicolumn{5}{|l|}{ Nerve invasion } \\
\hline Positive & 14 & 23 & 16 & 21 \\
\hline Negative & 5 & 3 & 6 & 2 \\
\hline \multicolumn{5}{|l|}{ Anterior invasion } \\
\hline Positive & 10 & 10 & 13 & 7 \\
\hline Negative & 9 & 16 & 9 & 16 \\
\hline \multicolumn{5}{|l|}{ Retroperitoneal invasion } \\
\hline Positive & 12 & 19 & 14 & 17 \\
\hline Negative & 7 & 7 & 8 & 6 \\
\hline \multicolumn{5}{|l|}{ Duodenal invasion } \\
\hline Positive & 11 & 16 & 14 & 13 \\
\hline Negative & 8 & 10 & 8 & 10 \\
\hline \multicolumn{5}{|l|}{ Choledochus invasion } \\
\hline Positive & 9 & 19 & 12 & 16 \\
\hline Negative & 10 & 7 & 10 & 7 \\
\hline \multicolumn{5}{|l|}{ Portal vein invasion } \\
\hline Positive & 4 & 8 & 7 & 5 \\
\hline Negative & 15 & 18 & 15 & 18 \\
\hline \multicolumn{5}{|l|}{ Extrapancreatic plexus invasion } \\
\hline Positive & 9 & 15 & 12 & 12 \\
\hline Negative & 10 & 11 & 10 & 11 \\
\hline
\end{tabular}


Heterotopic and orthotopic xenografted tumors in mice. Sixweek-old male nude mice (BALB/cA Jcl-nu/nu; CLEA Japan Inc., Tokyo, Japan) were subcutaneously injected in the right flank with $1 \times 10^{6}$ PANC-1 cells/mouse $(\mathrm{N}=8)$. Four weeks later, the mice were euthanized and the tumors were excised. Furthermore, to evaluate the orthotopic xenografted tumors of human pancreatic cancer cells, we used NOD/Shi-scid, IL- $2 \gamma^{\text {null }}$ (NOG; Central Institute for Experimental Animals, Kanagawa, Japan) mice (39). We injected $1 \times 10^{5}$ PANC-1 cells into the spleen of NOG mice $(\mathrm{N}=12)$, and then splenectomy was performed after $1 \mathrm{~min}$. Eight weeks later, 2 mice exhibited abdominal tumors in the area adjacent to the pancreas, and the pancreatic tumors were excised. Portions of the subcutaneous and pancreatic tumors were fixed in $4 \%$ paraformaldehyde for routine histopathological processing (40). Animal experiments were carried out according to the institutional animal care guidelines of the Nippon Medical School Animal Ethics Committee.

Transfection of small interfering RNA (siRNA). Pre-designed siRNA targeting mouse-nestin (siRNA ID: s70481), targeting human-nestin (s21143), and negative control siRNA (silencer select negative control no. 1) were obtained from Applied Biosystems, Inc. Sense and anti-sense mouse-nestin siRNA sequences were 5'-GACUGGUAGAGAAAGAGGA-3' and 5'-UCCUC UUUCUCUACCAGUC-3', respectively. Sense and anti-sense human nestin siRNA sequences were 5'-GACUGGUAGAG AAAGAGGA-3' and 5'-UCCUCUUUCUCUACCAGUC-3', respectively. Cells were transfected with the siRNAs in serumfree DMEM medium using TransIT-si-QUEST transfection reagent. In short, each siRNA stock solution and TransIT-siQUEST (2.5 $\mu 1 /$ well) were mixed in serum-free DMEM medium. After immediate mixing and incubation at room temperature (RT) for $15 \mathrm{~min}$, this siRNA-lipid complex was added to cultured cells $\left(2 \times 10^{5}\right.$ cells/ 6 -well plate). The cells were incubated for $24 \mathrm{~h}$ at $33^{\circ} \mathrm{C}$, then the medium was replaced with fresh DMEM containing $10 \%$ FBS. The treated cells were cultured for $48 \mathrm{~h}$ then collected for analyses. Prior to this examination, we tried to transfect the siRNAs at a concentration of 2.5-20 nM, and the appropriate concentration of siRNAs was determined as $5 \mathrm{nM}$ by quantitative reverse transcription-PCR (qRT-PCR). We tried two kinds of siRNAs for each to target mouse or human nestin to inhibit nestin expression (s70481 and s70479 for mouse; s21143 and s21141 for human), and stronger inhibitors of nestin expression (s70481 and s21143) were used in the present study.

$q R T-P C R$. Total RNA was extracted from cells using a FastPure RNA kit. One microgram of total RNA per sample was used for RT with a High-Capacity cDNA Reverse Transcription kit following the manufacturer's protocol. qRT-PCR for mousenestin (Mm03053244_s1), human-nestin (Hs00707120_s1) and 18S rRNA (Hs99999901_s1) was performed using the StepOnePlus PCR system (Applied Biosystems, Inc.) with specific primers and a TaqMan probe. PCR was carried out in $20-\mu 1$ reaction mixtures containing $10 \mu \mathrm{l}$ of $2 \mathrm{X}$ TaqMan Gene Expression Master Mix, $2 \mu \mathrm{l}$ of template cDNA, and $1 \mu \mathrm{l}$ of TaqMan Gene Expression Assays. Cycling conditions were as follows: $20 \mathrm{sec}$ at $95^{\circ} \mathrm{C}$ then 40 cycles for $1 \mathrm{sec}$ at $95^{\circ} \mathrm{C}$ followed by $20 \mathrm{sec}$ at $60^{\circ} \mathrm{C}$. qRT-PCR results were expressed as target/18S rRNA as an internal standard concentration ratio. Gene expression levels were always measured in triplicate.

Immunofluorescence analysis. TKD2 cells ( $1 \times 10^{5}$ cells) were plated on 35-mm glass-bottomed dishes and treated with siRNAs as described above. After $72 \mathrm{~h}$ of siRNA treatment, the cells were fixed in $4 \%$ paraformaldehyde solution for $15 \mathrm{~min}$ at RT. The fixed cells were treated with $50 \mathrm{mM}$ glycine for $5 \mathrm{~min}$, $0.1 \%$ Triton X-100 for $5 \mathrm{~min}$, and $10 \%$ rabbit serum for $30 \mathrm{~min}$ at RT. Next, the cells were incubated with a goat anti-mouse nestin antibody (dilution, 1:50) or a mouse anti-human nestin antibody (dilution, 1:50) overnight at $4^{\circ} \mathrm{C}$, followed by a FITClabeled anti-goat or Alexa 488-labeled donkey anti-mouse IgG antibody IgG antibody (dilution, 1:1000). Then the dishes were mounted with Vectashield H-1200 containing DAPI. The nestin protein expression of cells was observed under a Digital Eclipse C1 TE2000-E microscope (Nikon Insteck Co., Ltd., Kanagawa, Japan) with a blue diode (excitation, $405 \mathrm{~nm}$; emission, 450/35 nm) and an argon laser (excitation, $488 \mathrm{~nm}$; emission, 515/30 nm). Fluorescence images were acquired and analyzed using confocal microscope Digital Eclipse $\mathrm{C} 1$ control software EZ-C1 (Nikon Insteck Co., Ltd.). The confocal settings including laser power and detector sensitivity were unchanged during the acquisition of all images.

Cell proliferation assay. To examine the growth rates, a nonradioactive cell proliferation assay was performed. TKD2 cells $\left(5 \times 10^{3}\right.$ cells/well $)$ were seeded in 96-well plates, and incubated at $33^{\circ} \mathrm{C}$ in a humidified $5 \% \mathrm{CO}_{2}$ atmosphere for $24,48,72,96$ and $120 \mathrm{~h}$. Cells were then incubated with WST- 8 cell counting reagent for $4 \mathrm{~h}$ at $33^{\circ} \mathrm{C}$ and the optical density at $450 \mathrm{~nm}$ of the solution in the plate was measured using an ELISA plate reader (Bio-Rad Laboratory, Hercules, CA). All assays were performed in triplicate.

Next, we performed cell proliferation assays after administration of mouse or human-nestin siRNA. siRNA was administered to cell suspension and then cells $\left(1 \times 10^{4}\right.$ cells/well $)$ were plated in 6-well plate. After $96 \mathrm{~h}$, the cell number was counted using a C-Reader (Digital Bio Technology Co., Ltd., Kyungki-do, Korea). All assays were performed in triplicate.

Single-cell movement assay. To confirm the effects of nestin on cell migration, a single-cell movement assay was performed next as described previously (41). Briefly, TKD2 cells (5,000 cells/ well) were seeded onto 4 -well glass bottom dishes and grown for $48 \mathrm{~h}$. Cell movement was then monitored for $24 \mathrm{~h}$ by a Digital Eclipse TE-200-E motorized inverted microscope which photographed the cells every $5 \mathrm{~min}$. The total distance of individual cells covered within $24 \mathrm{~h}$ was determined using the MetaMorph software 7.6 (Universal Image Corp., Ltd., Buckinghamshire, $\mathrm{UK})$. Images from four areas in each well at magnification x100 were taken, and the movement all cells in the fields was analyzed. Approximately 100 cells in each well were analyzed for single-cell movement.

In vivo administration of siRNA targeting nestin. To examine the effect of reduced nestin expression on in vivo tumorigenicity, KLM-1 cells/animal $\left(1 \times 10^{6}\right)$ were injected subcutaneously into 6-week-old male nude mice. KLM-1 cells exhibited relatively low expression of human nestin; therefore, we used KLM-1 
cells to evaluate the effect of siRNA targeting mouse nestin in mouse vascular endothelial cells to avoid the possibility of cross-reaction of the mouse nestin siRNA to human nestin in vivo. Seven days after injection of KLM-1 cells, tumor cell-bearing mice were randomly divided into 3 groups (mousenestin siRNA, negative siRNA, and phosphate buffered saline (PBS) treated group. Each group contained three animals. To improve the efficiency of siRNA transfection in vivo, we used AteloGene (42). The siRNA and AteloGene mixture was injected directly into the tumor ( $1 \mathrm{nM}$ siRNA with $100 \mu \mathrm{l}$ of AteloGene). The injections were performed 3 times weekly. The quantity of siRNA and AteloGene, and the intervals and method of injection were performed according to the manufacturer's protocol. The animals were monitored for tumor formation then sacrificed 23 days after injection. Tumor volume was calculated using the following formula: volume $=\mathrm{a} \mathrm{x}^{2} \times 0.5$, where $\mathrm{a}$ is the longest diameter and $b$ is the shortest one. The tumors were removed, fixed in $20 \%$ neutral-buffered formalin, and embedded in paraffin. The sections $(3.5 \mu \mathrm{m})$ were used for immunohistochemical staining of mouse-nestin.

Statistical analyses. To analyze the correlations between clinicopathological factors and nestin-positive or CD34-positive endothelial cells, the $\chi^{2}$ test was used. The unpaired t-test or Mann Whitney U test was used to analyze the correlation between two groups. Disease-free survival curves were computed according to the Kaplan-Meier method; differences in survival were computed using the log-rank test. A $\mathrm{P}<0.05$ was considered significant. Computations were performed using the StatView J version 5.0 (SAS Institute, Inc., Cary, NC) software package.

\section{Results}

Immunohistochemical analyses of nestin and CD34 in normal and non-cancer human pancreatic tissues. We examined the localization of nestin and CD34 in non-cancer pancreatic tissue that were obtained from tissue sections of the heterotopic spleen of the pancreas and commercially-obtained normal pancreatic tissue. Nestin was not or rarely detected in vascular endothelial cells, whereas CD34 was detected in capillary endothelial cells in endocrine and exocrine pancreatic tissues (Fig. 1, arrows).

Immunohistochemical analysis of nestin in human PDAC tissues. Several vascular endothelial cells showed nestin expression in the areas near PDAC cells (Fig. 2A, arrowheads). To confirm the expression of nestin in vascular endothelial cells, immunostaining of common vascular endothelial markers, CD34, CD31 and factor VIII was performed in serial tissue sections (Fig. 2A), Nestin-positive vessels included only part of the CD34-, CD31, and factor VIII-positive vessels. Relatively small-sized vessels expressed nestin (Fig. 2A, arrowheads), whereas large-sized vessels did not express nestin (Fig. 2A, arrows). CD34, CD31 and factor VIII were expressed in both small- and large-sized blood vessels (Fig. 2A, arrowheads and arrows). $\alpha$-SMApositive smooth muscle cells (Fig. 2A, arrows) and elastic lamina (Fig. 2A, arrows) were located only in large-sized blood vessels. These results suggest that in the areas adjacent to PDAC cells, nestin is specifically expressed in small-sized blood vessels that do not possess thick walls with smooth muscle and elastic lamina.
Next, we determined whether nestin was expressed in lymphatic vessels. Nestin-positive vessels did not express D2-40 in human PDAC tissues (Fig. 2B, black arrowheads). By contrast, D2-40-positive lymph vessels did not express nestin (Fig. 2B, arrows). Both nestin and D2-40 were expressed in nerve fibers (Fig. 2B, white arrowheads). Staining patterns of LYVE-1 and VEGFR3 in PDAC tissues were similar to those of D2-40 (data not shown).

Immunohistochemical analyses of PCNA in nestin- or CD34-positive vessels in human PDAC tissues. We performed immunohistochemical analyses of PCNAs to compare the cell proliferative activity with nestin-positive or CD34-positive blood vessels in PDAC tissues. PCNA immunoreactivity was detected in the nuclei of most PDAC cells and some vascular endothelial cells. In serial tissue sections, nestin-positive vascular endothelial cells nearby PDAC cells co-expressed the proliferation marker, PCNA in their nucleus (Fig. 3A, arrowheads). We counted the number of PCNA-positive cells in nestin- and CD34-positive vascular endothelial cells (Fig. 3B), but there was no statistically significant difference in PCNA-positive cells between the two cell types. Next, we determined the PCNAlabeling indices of nestin-positive and nestin-negative vessels. Nestin-positive vessels showed higher PCNA labeling indices than nestin-negative vessels (Fig. 3C, P<0.05).

Analyses of the numbers and dimensions of nestin or CD34positive vessels using image analysis software. Nestin was also detected in a small number of spindle cells adjacent to PDAC cells, and the cells were stained with $\alpha$-SMA or S-100 in serial tissue sections (data not shown). Therefore, the number and dimensions of lumen-forming nestin-positive vessels or CD34positive vessels (Fig. 4A, arrows) were analyzed using the image analysis software WinROOF. Green areas in Fig. 4A indicate nestin- or CD34-positive vessels, respectively. The number of nestin- and CD34-positive vessels per field was 24.3 \pm 8.9 (3.0-77.0) and 120.8 2 2.6 (29.0-351.0), respectively. The number of nestin-positive vessels was $\sim 20 \%$ the number of CD34-positive vessels (Fig. 4B, $\mathrm{P}<0.0001$ ). The average dimension of nestin- and CD34-positive vessels was 200.8 \pm 20.1 (12.0-708.3) and 270.4 $\pm 33.6 \mu \mathrm{m}^{2}\left(97.1-1555.2 \mu \mathrm{m}^{2}\right)$, respectively. The average dimension of nestin-positive vessels was $\sim 75 \%$ that of CD34-positive vessels (Fig. 4C, $\mathrm{P}<0.05$ ). The total dimension of nestin- and CD34-positive vessels was $4.89 \times 10^{3} \pm 0.67 \times 10^{3}\left(84.3-18275.7 \mu \mathrm{m}^{2}\right)$ and $43.20 \times 10^{4}$ $\pm 0.52 \times 10^{4} \mu \mathrm{m}^{2}\left(6677.0-239494.3 \mu \mathrm{m}^{2}\right)$, respectively. The total dimension of nestin-positive vessels was $\sim 15 \%$ that of CD34positive vessels (Fig. 4D, $\mathrm{P}<0.0001$ ). These findings using image analysis software showed that nestin was expressed in a smaller number of blood vessels and in smaller-sized blood vessels than CD34.

Correlations between clinicopathological findings and nestin- or CD34-positive vessels. We divided PDAC cases into two groups by the median value of nestin- or CD34-positive vascular vessels. There were no statistically significant differences in histology, stage, vascular invasion of lymph duct invasion between groups with high and low numbers of nestin- or CD34-positive vessels (Table I). There were also no significant differences between nestin- or CD34-positive vessels and survival curves 


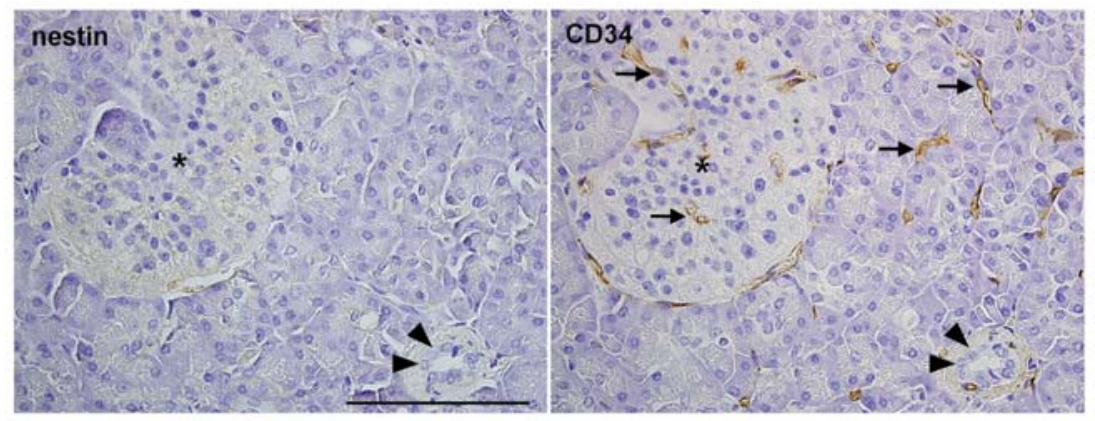

Figure 1. Immunohistochemical analyses of nestin and CD34 in normal human pancreatic tissues. In normal pancreatic tissues, nestin showed weak or absent expression, whereas CD34 was detected in capillary endothelial cells (arrows). Arrows, capillary endothelial cells; arrowheads, pancreatic ducts; asterisks, islets; scale bar, $100 \mu \mathrm{m}$.
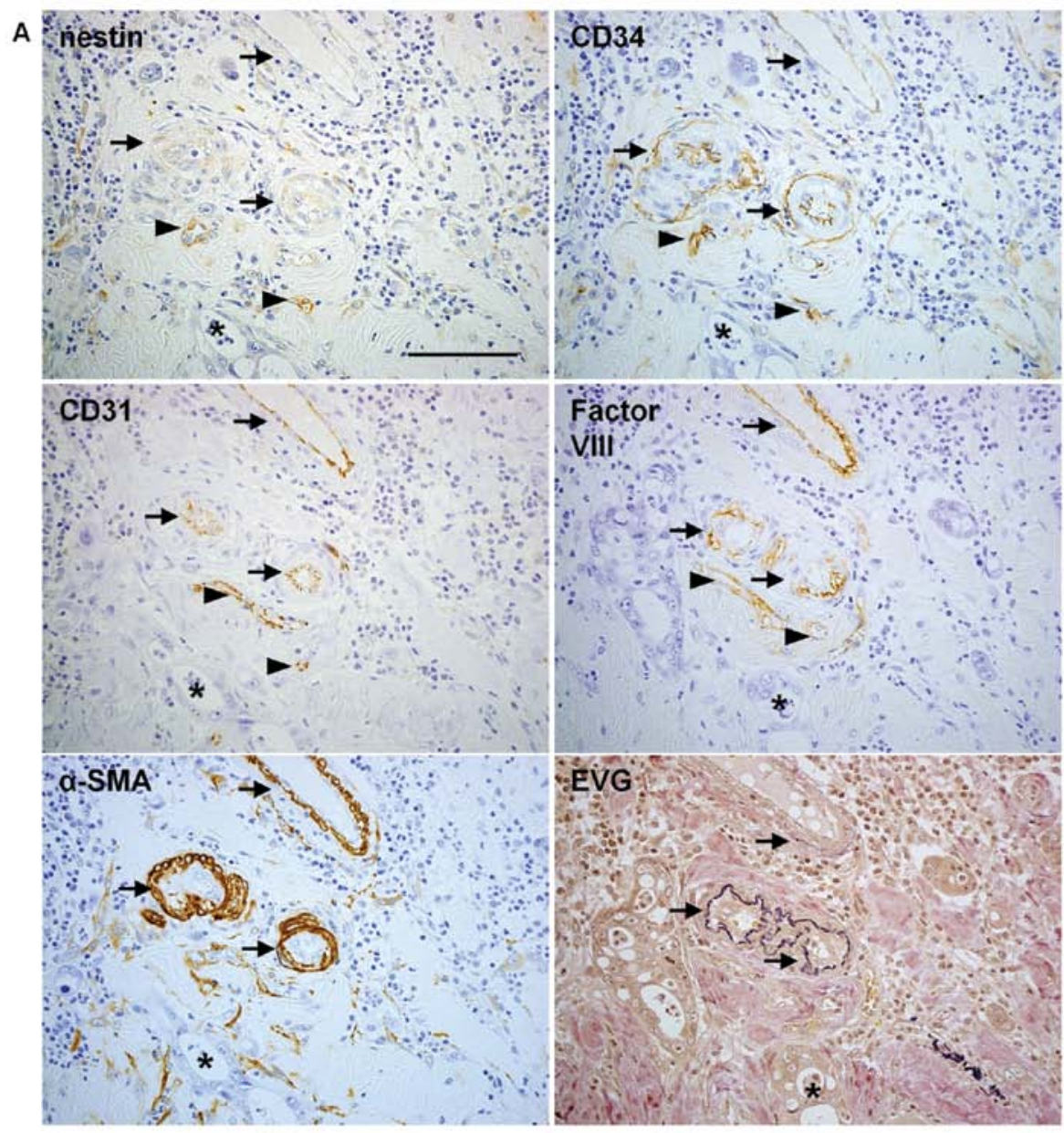

B
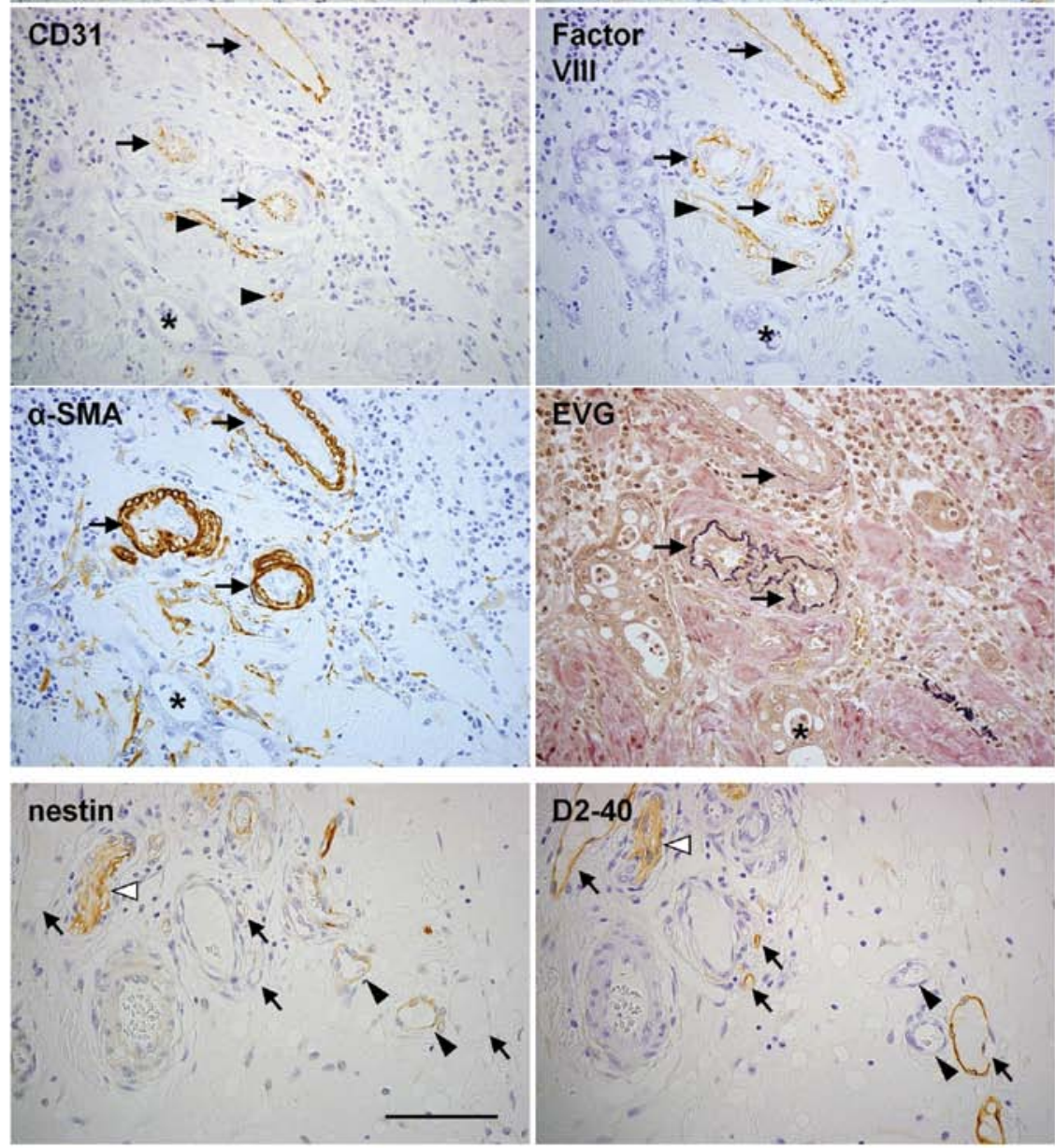

Figure 2. Immunohistochemical analyses of nestin and common vascular endothelial and lymphangioendothelial markers in human pancreatic ductal adenocarcinoma (PDAC) tissues. (A) In serial tissue section analyses, nestin was detected in small (arrowheads) but not large (arrows) vessels. CD34, CD31, and factor VIII were expressed in both small and large vessels (arrowheads and arrows, respectively). Large vessels stained for $\alpha$-SMA and elastic lamina in the vascular walls. (B) Nestin-positive vascular endothelial cells (black arrowheads) were negative for D2-40 (black arrowheads). In contrast, D2-40-positive lymph vessels (arrows) were negative for nestin (arrows). Black arrowheads, small-sized vessels; arrows, large-sized vessels; asterisks, cancer cells; white arrowheads, nerve fiber; scale bar, $100 \mu \mathrm{m}$. 
A
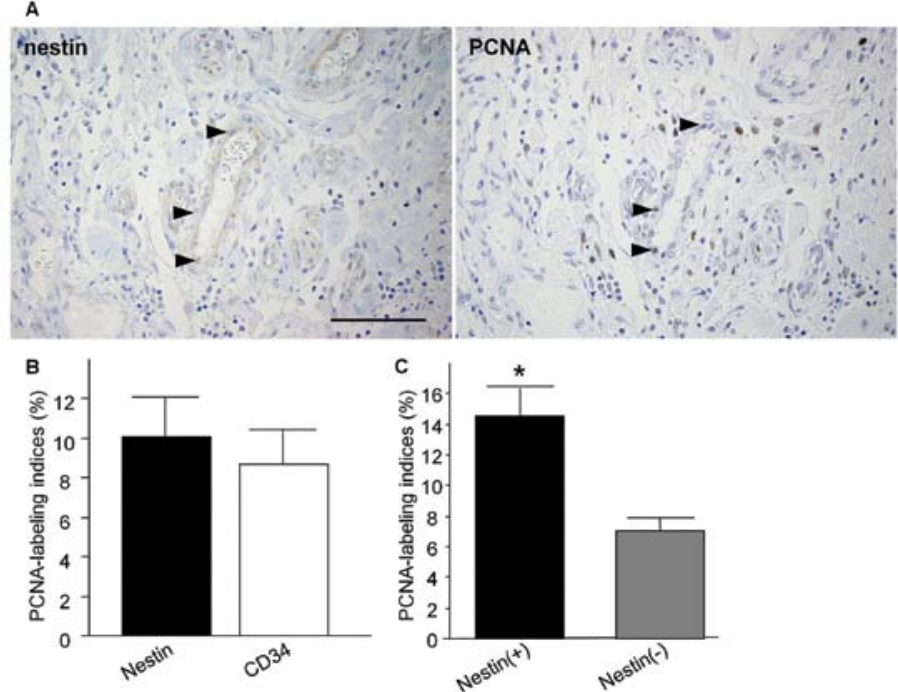

Figure 3. Proliferative ability of nestin- or CD34-positive blood vessels in human pancreatic ductal adenocarcinoma tissues. (A) PCNA-labeling indices of nestinor CD34-positive vessels were analyzed using serial tissue sections. Arrowheads, positive cells; scale bar, $100 \mu \mathrm{m}$. (B) The PCNA-labeling indices of nestin- and CD34-positive vessels. (C) The PCNA-labeling indices of nestin-positive and -negative vessels. "P<0.05.

A

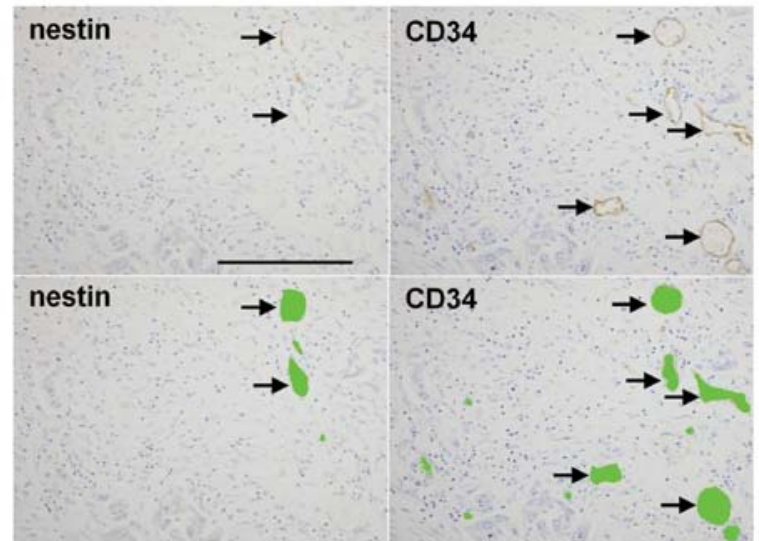

B

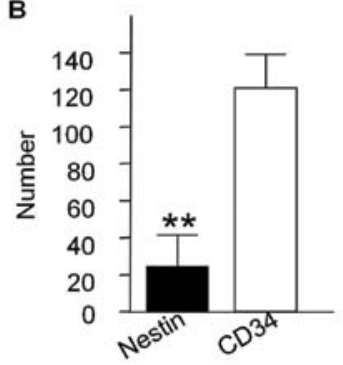

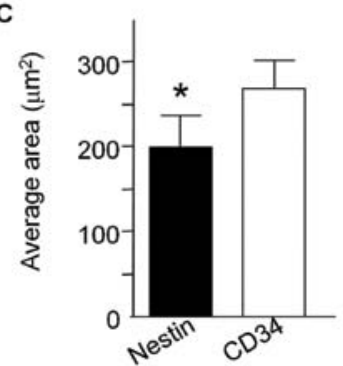

D

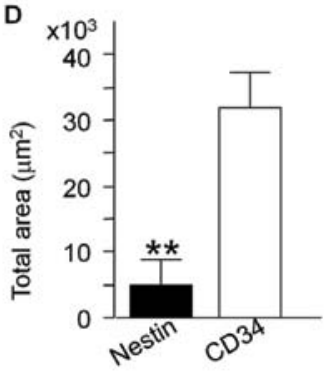

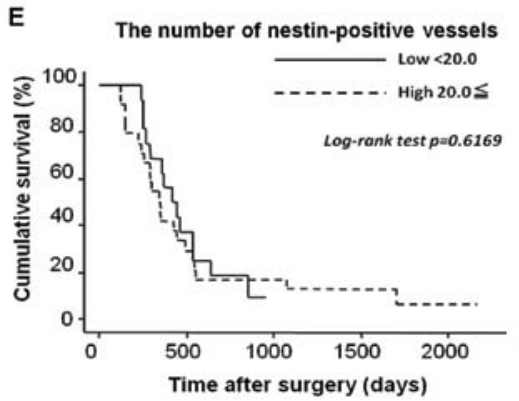

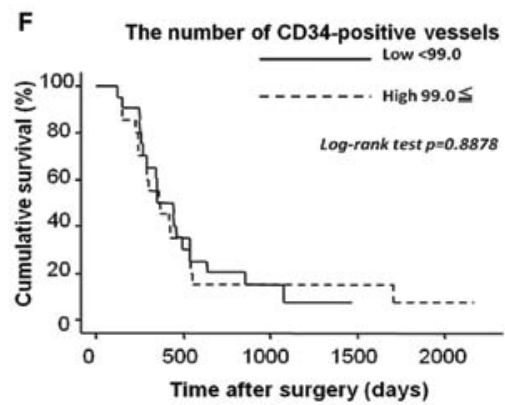

Figure 4. Image analysis of nestin- or CD34-positive vessels. (A) Using serial tissue sections, 5 nestin hot-spot areas adjacent to PDAC were analyzed for CD34. Upper panels show images of nestin- or CD-34 positive vessels (arrows). Lower panels show the corresponding images analyzed by image analysis software. Green areas indicate nestin- or CD34-positive blood vessels. Scale bar, $200 \mu \mathrm{m}$. (B) Number of nestin- and CD34-positive vessels ("*P<0.0001). (C) Average dimensions of nestin- and CD34-positive vessels ( $\mathrm{P}<0.05)$. (D) Total dimensions of nestin- and CD34-positive vessels ( $\left.{ }^{* *} \mathrm{P}<0.0001\right)$. (E) Cumulative Kaplan-Meier survival curves for all patients with high or low numbers of nestin-positive vessels. (F) Curves for all patients with high or low numbers of CD34-positive vessels. 
A
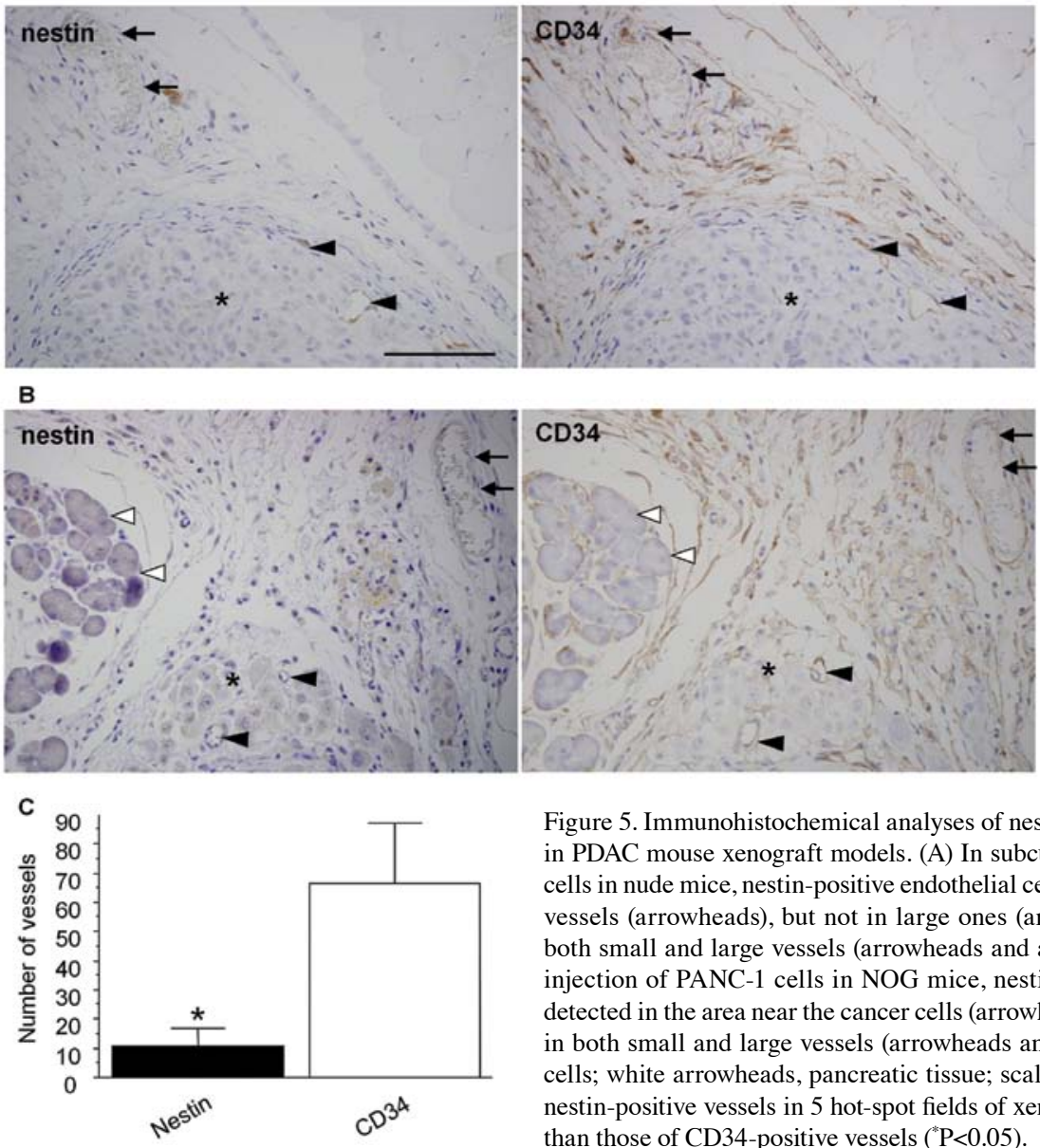

Figure 5. Immunohistochemical analyses of nestin and CD34 in tumor vessels in PDAC mouse xenograft models. (A) In subcutaneously-implanted PANC-1 cells in nude mice, nestin-positive endothelial cells were detected only in small vessels (arrowheads), but not in large ones (arrows). CD34 was detected in both small and large vessels (arrowheads and arrows). (B) After intrasplenic injection of PANC-1 cells in NOG mice, nestin-positive small vessels were detected in the area near the cancer cells (arrowheads), and CD34 was detected in both small and large vessels (arrowheads and arrows). Asterisks, PANC-1 cells; white arrowheads, pancreatic tissue; scale bar, $100 \mu \mathrm{m}$. (C) Number of nestin-positive vessels in 5 hot-spot fields of xenografted tumors were smaller than those of CD34-positive vessels $\left({ }^{*} \mathrm{P}<0.05\right)$.

(Fig. 4E and F), recurrence-free survival rate, or liver metastasisfree survival rate (data not shown).

Immunohistochemical analyses of nestin and CD34 in mice with xenografted human pancreatic cancers. We examined the nestin- and CD34-immunoreactivities in tumor blood vessels using mice with xenografted human PDAC cells. In subcutaneously-implanted PANC-1 cells, nestin-positive vascular endothelial cells were detected in small-sized vessels (Fig. 5A, arrowheads) but not in large-sized ones (arrows). In contrast, CD34 was detected in both small- and large-sized blood vessels (Fig. 5A, arrowheads and arrows, respectively). Eight weeks after the intrasplenic injection of PANC-1 cells, the cells formed intra-abdominal tumors very close to pancreatic tissues (Fig. 5B, asterisks). Nestin was detected in small-sized blood vessels (Fig. 5B, arrowheads) but not large-sized ones (arrows). On the other hand, CD34 was detected in both small- and large-sized blood vessels (Fig. 5B, arrows and arrowheads). By counting the 5 hot-spot fields nearby PDAC cells at magnification x 200 fewer nestin-positive vessels than CD34-positive vessels were seen in these areas (Fig. 5C, $\mathrm{P}<0.05$ ). These results suggest that nestin is specifically expressed in newly-formed tumor vessels in mouse xenograft models.

Effects of reduced nestin expression levels on cell growth and motility in vascular endothelial cells. Next, we examined the roles of nestin in vascular endothelial cells in vitro. siRNA targeting mouse-nestin transcripts was transfected into TKD2 cells, which are mouse immortalized vascular endothelial cells. siRNA targeting human-nestin transcripts was transfected into HUVEC-2 cells, which are human primary vascular endothelial cells. Nestin siRNA targeting mouse or human-nestin transcripts reduced the expression of nestin mRNA in TKD2 or HUVEC-2 cells compared with the levels in cells not treated with siRNA (untreated) and negative siRNA-transfected cells, respectively (siNegative, Fig. 6A). Immunocytochemically, nestin protein levels were also decreased in siNestin cells compared with siNegative cells (Fig. 6B). Cell morphology was not altered by treatment with nestin siRNA or negative siRNA.

We examined whether reduced nestin expression affects the growth and migration activities of vascular endothelial cells. In TKD2 cells, the growth rate of siNestin cells was markedly inhibited compared with that of siNegative cells and untreated cells, and the difference was statistically significant at 96 and $120 \mathrm{~h}$ (Fig. 6C, P<0.05). Next, we confirmed the growthinhibitory effects of nestin siRNA in TKD2 and HUVEC-2 cells using a cell-counting method. Nestin siRNA transfection in the vascular endothelial cells induced a significant decrease in cell number after $96 \mathrm{~h}\left({ }^{*} \mathrm{P}<0.05\right.$, Fig. 6D).

To determine cell migration ability, single-cell movement was monitored by time-lapse microscopy; however, no significant difference in TKD2 cell motility between siNestin cells and siNegative cells was observed (Fig. 6E and F).

Effects of reduced nestin expression levels on tumor growth in nude mice. In mouse TKD2 endothelial cells, siNestin at 
A

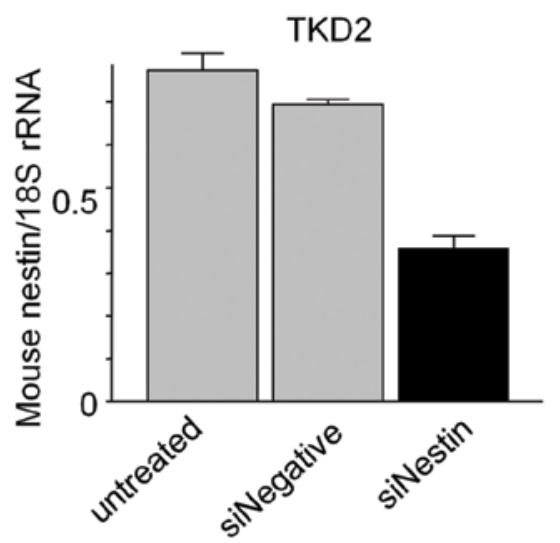

B

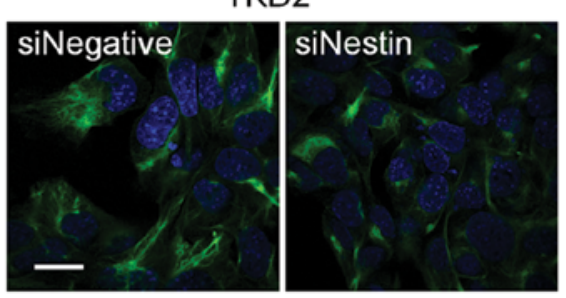

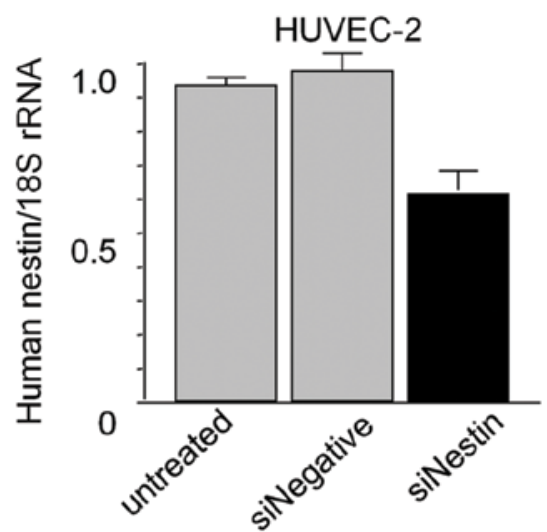

HUVEC-2

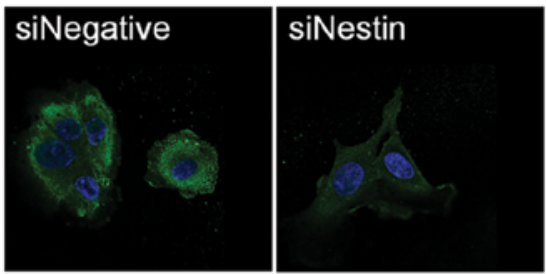

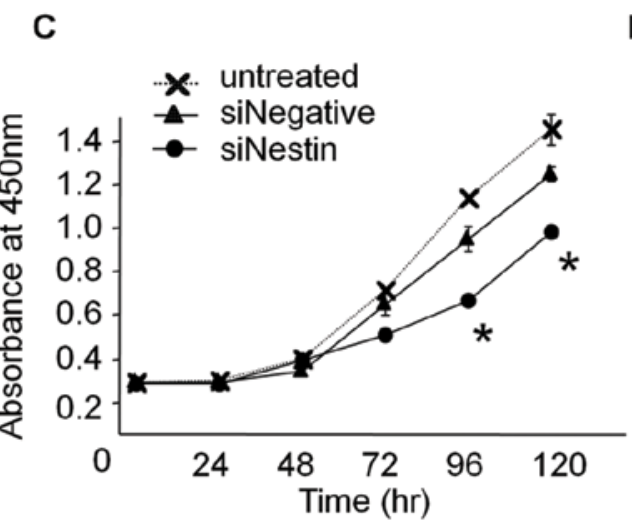
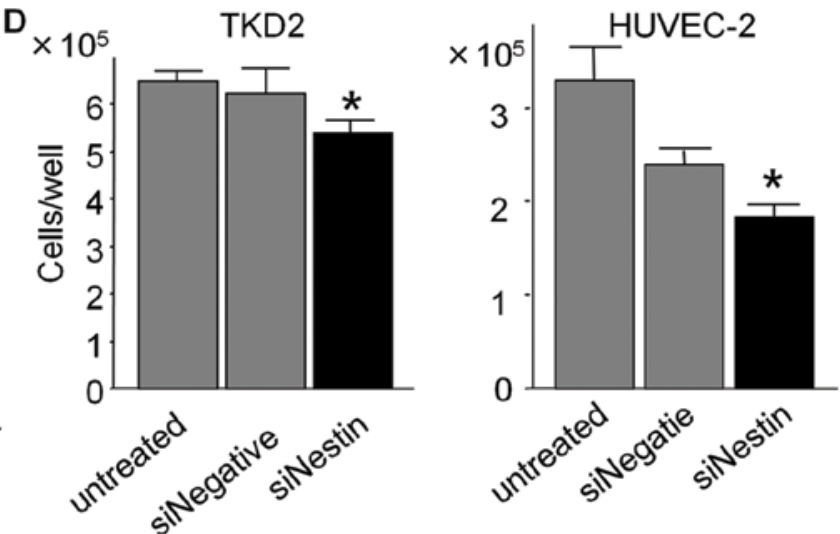

E
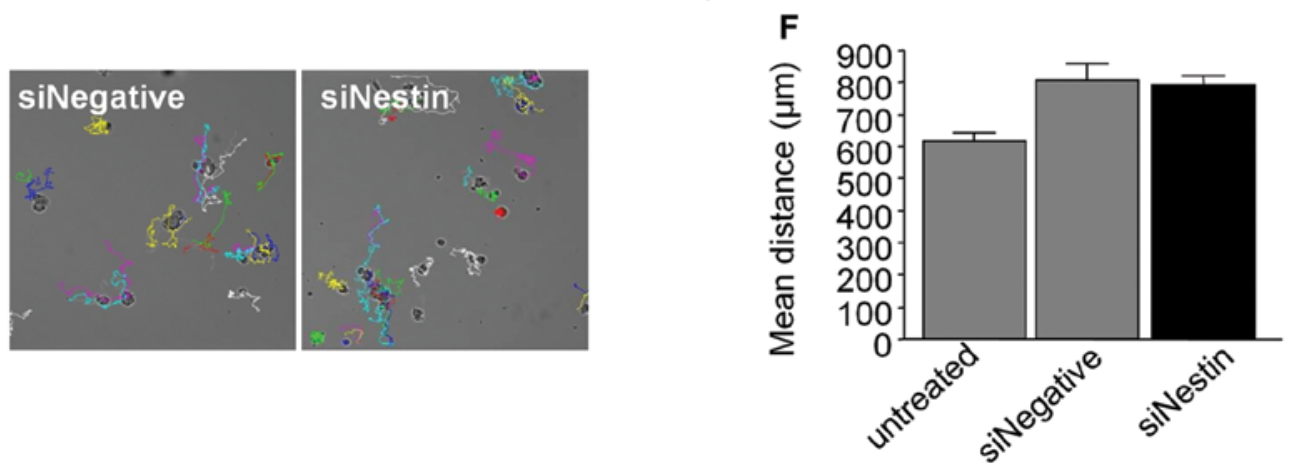

Figure 6. Cell proliferation and migration assays in nestin siRNA-transfected vascular endothelial cells. (A) Nestin mRNA levels were significantly decreased in mouse immortalized endothelial TKD2 and human umbilical vein endothelial cells (HUVEC-2) transfected with siRNA targeting mouse or humannestin (siNestin), but nestin expression was not altered in TKD2 and HUVEC-2 cells transfected with negative siRNA (siNegative) or in untreated cells. (B) Immunocytochemistry showed that nestin protein levels were decreased in the siNestin cells compared with siNegative cells. Green, nestin; blue, nuclei; scale bar, $20 \mu \mathrm{m}$. (C) In TKD2 cells, siNestin inhibited in vitro cell growth compared with growth in siNegative and untreated cells ("P<0.05). (D) Number of TKD2 and HUVEC-2 cells with siNestin were decreased compared with those in siNegative and untreated cells $96 \mathrm{~h}$ after transfection $\left({ }^{*} \mathrm{P}<0.05\right)$. (E and F) Changes related to treatment were not observed in representative images of single-cell movement of TKD2 cells (E), and the total distance covered by individual cells within $24 \mathrm{~h}$ (F).

a concentration of 5 and $10 \mathrm{nM}$ markedly decreased nestin mRNA expression (Fig. 7A). In contrast, negative siRNA at the concentration of $10 \mathrm{nM}$ did not decrease nestin mRNA expression in TKD2 cells. In human KLM-1 PDAC cells, which express human nestin mRNA, siRNA targeting mouse-nestin did not affect human nestin expression levels (Fig. 7B). Next, we examined whether siNestin could inhibit human PDAC cell growth in vivo via anti-angiogenic effects on mouse tumor 
A

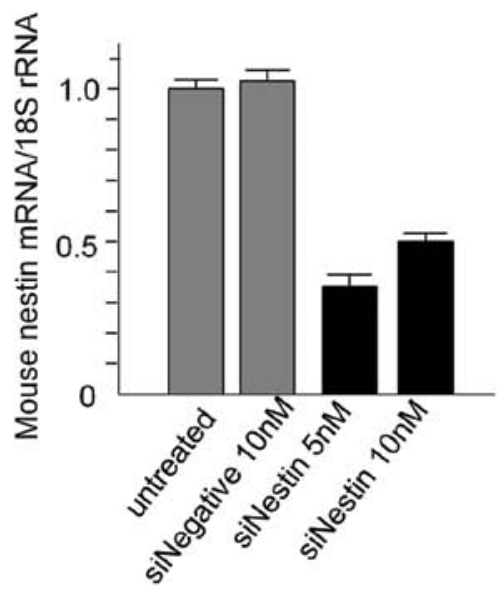

B

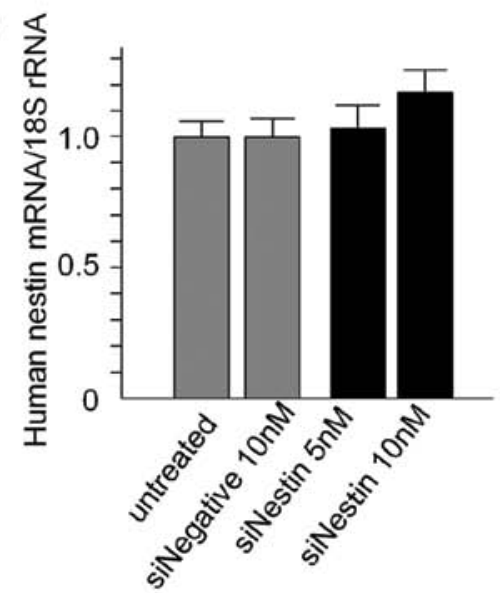

C

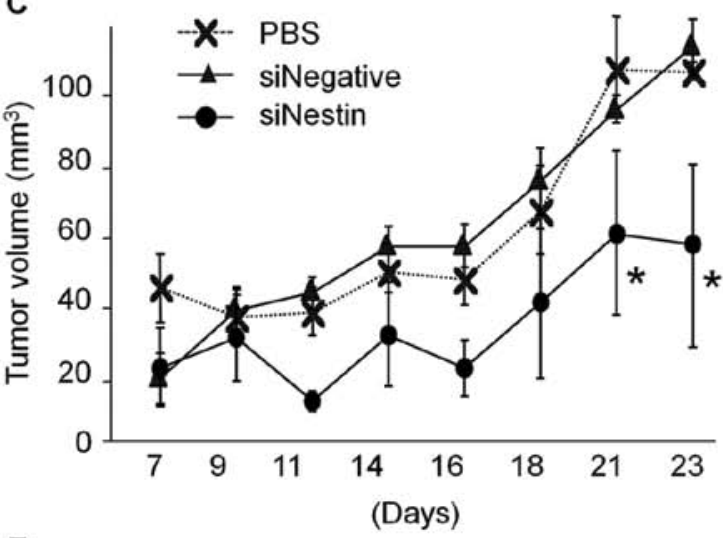

D siNegative

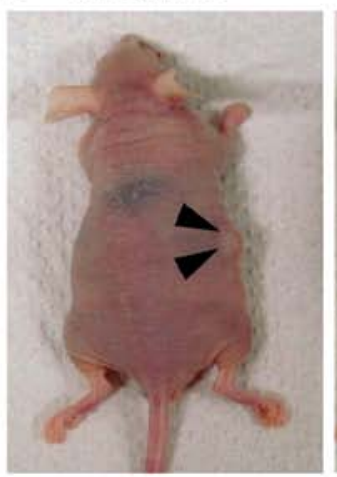

siNestin

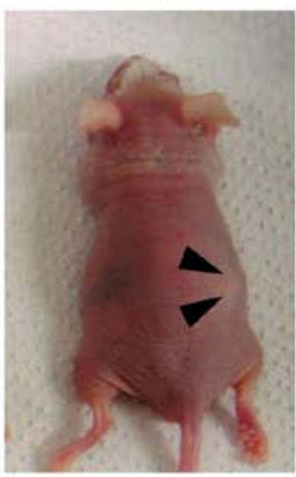

$F$

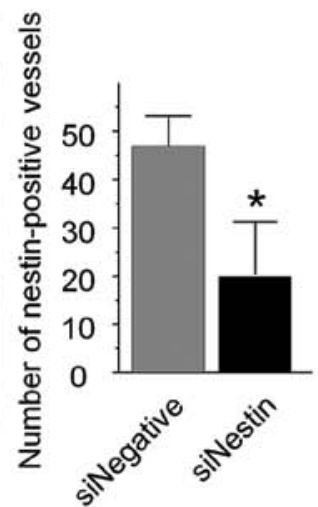

Figure 7. In vivo transfection of siRNA targeting mouse nestin in subcutaneously transplanted human pancreatic ductal adenocarcinoma in nude mice. (A and B) In vitro confirmation of the silencing effect of siRNA targeting mouse nestin. Mouse-nestin mRNA was significantly decreased in the mouse immortalized endothelial TKD2 cell line transfected with siRNA targeting mouse-nestin (siNestin), but not significantly altered in TKD2 cells transfected with negative siRNA (siNegative) or in untreated cells (A). siNestin targeting mouse-nestin did not decrease the expression of human nestin in KLM-1, a human PDAC cell line (B). (C) siNestin was injected into subcutaneous tumors 3 times weekly with AteloGene. siNestin decreased subcutaneous tumor volume compared with tumors in the siNegative and PBS-treated groups ("P<0.05). (D) Characteristic subcutaneous tumors in nude mice of the siNestin and siNegative groups. (E) Immunohistochemical analyses showed that there were many nestin-positive blood vessels (arrows) in areas adjacent to the tumors (asterisk) in the siNegative group, but most of vessels in the siNestin group showed decreased expression of nestin (arrowheads). Asterisk, KLM-1 cells; scale bar, $100 \mu \mathrm{m}$. (F) The number of nestin-positive vessels in 5 hot-spot areas were significantly decreased in the siNestin group $\left({ }^{*} \mathrm{P}<0.05\right)$.

vessels. To improve the efficiency of in vivo transfection of siRNAs, we injected siRNA into subcutaneous tumors with AteloGene, according to the manufacturer's protocol. siNestin significantly inhibited tumor growth in vivo compared with the siNegative and PBS-treated groups (Fig. $7 \mathrm{C}$ and $\mathrm{D}, \mathrm{P}<0.05$ ). To confirm the silencing effect of siNestin at the protein level, we performed immunostaining of nestin in siRNA-treated mouse tumors. Immunohistochemically, many nestin-positive vessels were detected in subcutaneous tumors in the siNegative group (Fig. 7E, arrows), whereas only a few nestin-positive vessels were detected in the areas adjacent to PDAC cells in the siNestin group (arrowheads). The number of nestin-positive vessels were significantly decreased in siNestin group when compared with the siNegative group (Fig. 7F, $\mathrm{P}<0.05$ ). 


\section{Discussion}

CD34, CD31 and factor VIII are commonly used as vascular endothelial markers to determine MVD; however, which marker is best suited to analyze MVD has been controversial (43-45). To determine MVD in PDAC tissues, CD34 is more commonly used than CD31 or factor VIII $(14,15,46,47)$. Therefore, we compared the expression of nestin and CD34 in newly-formed blood vessels in PDAC tissues. The expression of nestin was specific to small, highly proliferative blood vessels in PDAC tissues, whereas CD34 was expressed in all-sized vessels. Previously, some endothelial cells and lymphangioendothelial cells were reported to express both lymphangioendothelial and vascular endothelial cell markers. However, nestin-positive endothelial cells in PDAC did not express all of the lymphangioendothelial markers examined. These findings suggest that nestin expression is specifically expressed in proliferating vascular endothelial cells, consistent with a previous report (48).

We compared the relationship between MVD of nestinpositive vessels and clinicopathological factors, but there was no statistically significant difference. The MVD of CD34-positive vessels also showed no relationship with clinicopathological factors. Several reports show that the MVD in PDAC determined with the hot-spot method using factor VIII or CD34 correlated with poor prognosis (49-51). In contrast, several reports showed that MVD determined with the hot-spot method using factor VIII or CD34 does not correlate with prognosis or liver metastasis $(52,53)$ and that the lumen method using factor VIII is superior to the hot-spot method $(14,15)$. Furthermore, it has been shown that a close relationship exists between intratumoral MVD and prognosis using CD34 in 104 PDAC patients (51). These data indicate that reference methods for measuring tumor angiogenesis are still controversial. In the present study, nestin was expressed in smaller-sized and highly-proliferative endothelial cells rather than with other commonly used angiogenic markers; thus, large-scale clinical research might be needed to clarify the effectiveness of MVD using nestin-positive vessels in PDAC.

Reducing nestin expression in endothelial cells with nestin siRNA inhibited proliferation; therefore, nestin is important for the growth of the vascular endothelium, and might be a therapeutic target for inhibiting tumor angiogenesis. Nestin contributes to the disassembly of vimentin during mitosis (54) inactivates the proapoptotic cyclin-dependent kinase 5 (55) and modulates mitosis-associated cytoplasmic reorganization during mitosis after becoming phosphorylated on $\mathrm{Thr}^{316}$ by cdc2 kinase (56). Down-regulating nestin expression in neural progenitor cells inhibited cyclin D1/E expression (57). The nestin gene has four exons and three introns. Neural cell-specific expression is reported to be regulated by the second intron, whereas nestin expression in tumor endothelium is enhanced by the first intron. These observations suggest that nestin in tumor endothelium is not only a structural protein, but also closely correlated with endothelial cell proliferation (48).

The effectiveness of anti-angiogenic agents for cancer treatment has been widely reported. The present study indicates that nestin inhibits the growth of mouse vascular endothelial cells in vitro and in vivo. In addition, nestin inhibits the growth of human primary cultured vascular endothelial cells in vitro. Thus, nestin may serve as a novel therapeutic target in PDAC angiogenesis similar to VEGFR inhibitors (58). Furthermore, expression of nestin in PDAC cells was detected in approximately $30 \%$ of PDAC cases (22). Recently, we have reported that reduced expression level of nestin in PDAC cells attenuated migration, invasion and metastasis (59). Therefore, nestin may become a new molecular target for both PDAC cells and tumor angiogenesis for nestin-expressing PDAC cases.

In conclusion, nestin was expressed in small growing blood vessels in pancreatic cancer tissues, and may be a useful marker of angiogenesis in PDAC tissues. Furthermore, nestin may be a novel therapeutic target in pancreatic cancers.

\section{Acknowledgement}

We thank Dr Masahito Hagio, Dr Junji Ueda, Mr. Tetsushi Yamamoto, Mr. Takenori Fujii, Ms. Taeko Suzuki, Ms. Kiyoko Kawahara, and Ms. Yoko Kawamoto (Departments of Pathology and Integrative Oncological Pathology) for excellent technical assistance, and Dr Takayuki Aimoto and Dr Yoshiharu Nakamura (Surgery for Organ and Biological Regulation) for helpful discussions. We also thank Dr Shin-ichi Tsuchiya (Division of Surgical Pathology) for preparing tissue blocks. This work was supported by a research grant from Pancreas Research Foundation of Japan to K. Yamahatsu, and Grants-in-Aid for Young Scientists (A, No. 22689038 to Y. Matsuda) and a Grantin-Aid for Scientific Research (C, No. 22591531 to T. Ishiwata) from Japan Society for Promotion of Science.

\section{References}

1. Jemal A, Siegel R, Ward E, Murray T, Xu J and Thun MJ: Cancer statistics, 2007. CA Cancer J Clin 57: 43-66, 2007.

2. Warshaw AL and Fernandez-del Castillo C: Pancreatic carcinoma. N Engl J Med 326: 455-465, 1992.

3. Ikeda N, Adachi M, Taki T, Huang C, Hashida H, Takabayashi A Sho M, Nakajima Y, Kanehiro H, Hisanaga M, Nakano H and Miyake M: Prognostic significance of angiogenesis in human pancreatic cancer. Br J Cancer 79: 1553-1563, 1999.

4. Kuwahara K, Sasaki T, Kuwada Y, Murakami M, Yamasaki S and Chayama K: Expressions of angiogenic factors in pancreatic ductal carcinoma: a correlative study with clinicopathologic parameters and patient survival. Pancreas 26: 344-349, 2003.

5. Liotta LA, Saidel MG and Kleinerman J: The significance of hematogenous tumor cell clumps in the metastatic process. Cancer Res 36: 889-894, 1976.

6. Hansen S, Grabau DA, Rose C, Bak M and Sorensen FB: Angiogenesis in breast cancer: a comparative study of the observer variability of methods for determining microvessel density. Lab Invest 78: 1563-1573, 1998

7. Schoell WM, Pieber D, Reich O, Lahousen M, Janicek M, Guecer F and Winter R: Tumor angiogenesis as a prognostic factor in ovarian carcinoma: quantification of endothelial immunoreactivity by image analysis. Cancer 80: 2257-2262, 1997.

8. Tanigawa N,Matsumura M,Amaya H, Kitaoka A,Shimomatsuya T, Lu C, Muraoka R and Tanaka T: Tumor vascularity correlates with the prognosis of patients with esophageal squamous cell carcinoma. Cancer 79: 220-225, 1997.

9. Tanigawa N, Amaya H, Matsumura M and Shimomatsuya T: Association of tumour vasculature with tumour progression and overall survival of patients with non-early gastric carcinomas. $\mathrm{Br}$ J Cancer 75: 566-571, 1997.

10. Takahashi Y, Tucker SL, Kitadai Y, Koura AN, Bucana CD, Cleary KR and Ellis LM: Vessel counts and expression of vascular endothelial growth factor as prognostic factors in node-negative colon cancer. Arch Surg 132: 541-546, 1997.

11. Wakui S, Furusato M, Itoh T, et al: Tumour angiogenesis in prostatic carcinoma with and without bone marrow metastasis: a morphometric study. J Pathol 168: 57-62, 1992.

12. Macchiarini P, Fontanini G, Hardin MJ, Squartini F and Angeletti CA: Relation of neovascularisation to metastasis of non-small-cell lung cancer. Lancet 340: 145-146, 1992. 
13. Srivastava A, Laidler P, Hughes LE, Woodcock J and Shedden EJ: Neovascularization in human cutaneous melanoma: a quantitative morphological and Doppler ultrasound study. Eur J Cancer Clin Oncol 22: 1205-1209, 1986.

14. Takagi K, Takada T, Amano H, Yoshida M, Miura H, Toyota N, Wada K and Takahashi I: Analysis of microvessels in pancreatic cancer: by light microscopy, confocal lser scan microscopy, and electron microscopy. J Hepatobiliary Pancreat Surg 15: 384-390, 2008.

15. Takagi K, Takada T and Amano H: A high peripheral microvessel density count correlates with a poor prognosis in pancreatic cancer. J Gastroenterol 40: 402-408, 2005.

16. Meert AP, Paesmans M, Martin B, Delmotte P, Berghmans T, Verdebout JM, Lafitte JJ, Mascoux C and Sculier JP: The role of microvessel density on the survival of patients with lung cancer: a systematic review of the literature with meta-analysis. Br J Cancer 87: 694-701, 2002.

17. Lendahl U, Zimmerman LB and McKay RD: CNS stem cells express a new class of intermediate filament protein. Cell 60: 585-595, 1990.

18. Sejersen T and Lendahl U: Transient expression of the intermediate filament nestin during skeletal muscle development. J Cell Sci 106: 1291-1300, 1993

19. Frojdman K, Pelliniemi LJ, Lendahl U, Virtanen I and Eriksson JE: The intermediate filament protein nestin occurs transiently in differentiating testis of rat and mouse. Differentiation 61: 243-249, 1997.

20. Terling C, Rass A, Mitsiadis TA, Fried K, Lendahl U and Wroblewski J: Expression of the intermediate filament nestin during rodent tooth development. Int J Dev Biol 39: 947-956, 1995.

21. Strojnik T, Rosland GV, Sakariassen PO, Kavalar R and Lah T: Neural stem cell markers, nestin and musashi proteins, in the progression of human glioma: correlation of nestin with prognosis of patient survival. Surg Neurol 68: 133-143, 2007.

22. Kawamoto M, Ishiwata T, Cho K, Uchida E, Korc M, Naito Z and Tajiri T: Nestin expression correlates with nerve and retroperitoneal tissue invasion in pancreatic cancer. Hum Pathol 40: 189-198, 2009

23. Tsujimura T, Makiishi-Shimobayashi C, Lundkvist J, et al: Expression of the intermediate filament nestin in gastrointestinal stromal tumors and interstitial cells of Cajal. Am J Pathol 158: 817-823, 2001.

24. Kleeberger W, Bova GS, Nielsen ME, Herawi M, Chuang AY, Epstein JI and Berman DH: Roles for the stem cell associated intermediate filament Nestin in prostate cancer migration and metastasis. Cancer Res 67: 9199-9206, 2007.

25. Li H, Cherukuri P, Li N, Cowling V, Spinella M, Cole M, Godwin AK, Wells W and Di Renzo J: Nestin is expressed in the basal/myoepithelial layer of the mammary gland and is a selective marker of basal epithelial breast tumors. Cancer Res 67: 501-510, 2007.

26. Brychtova S, Fiuraskova M,Hlobilkova A, Brychta T and Hirnak J: Nestin expressionin cutaneous melanomas and melanocytic nevi. J Cutan Pathol 34: 370-375, 2007.

27. Sellheyer K, Nelson P and Krahl D: Dermatofibrosarcoma protuberans: a tumour of nestin-positive cutaneous mesenchymal stem cells? Br J Dermatol 161: 1317-1322, 2009.

28. Yamada H, Takano T, Ito Y, Matsuzuka F, Miya A, Kobayashi K, Yoshida H, Watanabe M, Iwatani Y and Miyauchi A: Expression of nestin mRNA is a differentiation marker in thyroid tumors. Cancer Lett 280: 61-64, 2009.

29. Teranishi N, Naito Z, Ishiwata T, Tanaka N, Furukawa K, Seya T, Shinji $\mathrm{S}$ and Tajiri T: Identification of neovasculature using nestin in colorectal cancer. Int J Oncol 30: 593-603, 2007.

30. Mokry J, Cizkova D, Filip S, Ehrmann J, Osterreicher J, Kolar Z and English D: Nestin expression by newly formed human blood vessels. Stem Cells Dev 13: 658-664, 2004

31. Sugawara K, Kurihara H, Negishi M, Saito N, Nakazato Y, Sasaki T and Takeuchi T: Nestin as a marker for proliferative endothelium in gliomas. Lab Invest 82: 345-351, 2002.

32. Kim HS, Kang HS, Messam CA, Min KW and Park CS: Comparative evaluation of angiogenesis in gastric adenocarcinoma by nestin and CD34. Appl Immunohistochem Mol Morphol 10: $121-127,2001$

33. Ishiwata T, Matsuda $Y$ and Naito Z: Roles of nestin in gastro-intestinal and other cancers: effects on cells and tumor angiogenesis. World J Gastroenterol 17: 409-418, 2010
34. Ishiwata T, Kudo M, Onda M, Fujii T, Teduka K, Suzuki T, Korc M and Naito Z: Defined localization of nestin-expressing cells in L-arginine-induced acute pancreatitis. Pancreas 32: 360-368, 2006.

35. Sarlomo-Rikala M, Tsujimura T, Lendahl U and Miettinen $M$ Patterns of nestin and other intermediate filament expression distinguish between gastrointestinal stromal tumors, leiomyomas and schwannomas. APMIS 110: 499-507, 2002.

36. Gravdal K, Halvorsen OJ, Haukaas SA and Akslen LA: Proliferation of immature tumor vessels is a novel marker of clinical progression in prostate cancer. Cancer Res 69: 4708-4715, 2009.

37. Vermeulen PB, Gasparini G, Fox SB, Toi M, Martin L, McCulloch P, Pezzella F, Viale G, Weidner N, Harris AL and Dirix LY: Quantification of angiogenesis in solid human tumours: an international consensus on the methodology and criteria of evaluation. Eur J Cancer 32A: 2474-2484, 1996.

38. Hatanaka Y, Hashizume K, Nitta K, Kato T, Itoh I and Tani Y: Cytometrical image analysis for immunohistochemical hormone receptor status in breast carcinomas. Pathol Int 53: 693-699, 2003.

39. Suemizu H, Monnai M, Ohnishi Y, Ito M, Tamaoki $N$ and Nakamura M: Identification of a key molecular regulator of liver metastasis in human pancreatic carcinoma using a novel quantitative model of metastasis in NOD/SCID/gammacnull (NOG. mice. Int J Oncol 31: 741-751, 2007.

40. Matsuda Y, Fujii T, Suzuki T, Yamahatsu K, Kawahara K, Teduka K, Kawamoto Y, Yamamoto T, Ishiwata T and Naito Z: Comparison of fixation methods for preservation of morphology, RNAs, and proteins from paraffin-embedded human cancer cell-implanted mouse models. J Histochem Cytochem 59: 68-75, 2011.

41. Kawase R, Ishiwata T, Matsuda Y, Onda M, Kudo M, Takeshita T and Naito Z: Expression of fibroblast growth factor receptor 2 IIIc in human uterine cervical intraepithelial neoplasia and cervical cancer. Int J Oncol 36: 331-340, 2010.

42. Minakuchi Y, Takeshita F, Kosaka N, Sasaki H, Yamamoto Y, Kouno M, Honma K, Nagahara S, Hanai K, Sano A, Kato T, Terada $\mathrm{M}$ and Ochiya T: Aterocollagen-mediated synthetic small interfering RNA. Nucleic Acids Res 32: e109, 2004.

43. Uzzan B, Nicolas P, Cucherat M and Perret GY: Microvessel density as a prognostic factor in women with breast cancer: a systematic review of the literature and meta-analysis. Cancer Res 64: 2941-2955, 2004

44. Sullivan CA, Ghosh S, Ocal IT, Camp RL, Rimm DL and Chung GG: Microvessel area using automated image analysis is reproducible and is associated with prognosis in breast cancer. Hum Pathol 40: 156-165, 2009.

45. Norrby K and Ridell B: Tumour-type-specific capillary endothelial cell stainability in malignant B-cell lymphomas using antibodies against CD31, CD34 and factor VIII. APMIS 111: 483-489, 2003.

46. Yano T, Tanikawa S, Fujie T, Masutani M and Horie T: Vascular endothelial growth factor expression and neovascularisation in non-small cell lung cancer. Eur J Cancer 36: 601-609, 2000.

47. Offersen BV, Pfeiffer P, Hamilton-Dutoit S and Overgaard J: Patterns of angiogenesis in nonsmall-cell lung carcinoma. Cancer 91: 1500-1509, 2001.

48. Aihara M, Sugawara K, Torii S, Hosaka M, Kurihara H, Saito N and Takeuchi T: Angiogenic endothelium-specific nestin expression is enhanced by the first intron of the nestin gene. Lab Invest 84: 1581-1592, 2004.

49. Niedergethmann M, Hildenbrand R, Wolf G, Verbeke CS, Richter A and Post S: Angiogenesis and cathepsin expression are prognostic factors in pancreatic adenocarcinoma after curative resection. Int J Pancreatol 28: 31-39, 2000

50. Karademir S, Sokmen S, Terzi C, Sagoi O, Ozer E, AstarciogluH, Coker A and Astarcioglu I: Tumor angiogenesis as a prognostic predictor in pancreatic cancer. J Hepatobiliary Pancreat Surg 7: 489-495, 2000

51. Fujioka S, Yoshida K, Yanagisawa S, Kawakami M, Aoki T and Yamazaki Y: Angiogenesis in pancreatic carcinoma: thymidine phosphorylase expression in stromal cells and intratumoral microvessel density as independent predictors of overall and relapse-free survival. Cancer 92: 1788-1797, 2001.

52. Ellis LM, Takahashi Y, Fenoglio CJ, Cleary KR, Bucana CD and Evans DB: Vessel counts and vascular endothelial growth factor expression in pancreatic adenocarcinoma. Eur J Cancer 34: 337-340, 1998. 
53. Fujimoto K, Hosotani R, Wada M, Lee JU, Koshiba T, Miyamoto Y, Tsuji S, Nakajima S, Doi R and Iwamura M: Expression of two angiogenic factors, vascular endothelial growth factor and plateletderived endothelial cell growth factor in human pancreatic cancer, and its relationship to angiogenesis. Eur J Cancer 34: 1439-1447, 1998.

54. Chou YH, Khuon S, Herrmann H and Goldman RD: Nestin promotes the phosphorylation-dependent disassembly of vimentin intermediate filaments during mitosis. Mol Biol Cell 14: 1468-1478, 2003.

55. Huang YL, Wu CM, Shi GY, Wu GC, Lee H, Jiang MJ, Wu HL and Yang HY: Nestin serves as a prosurvival determinant that is linked to the cytoprotective effect of epidermal growth factor in rat vascular smooth muscle cells. J Biochem 146: 307-315, 2009.

56. Sahlgren CM, Mikhailov A, Hellman J, Cho YH, Lendahl U, Goldman RD and Eriksson JE: Mitotic reorganization of the intermediate filament protein nestin involves phosphorylation by cdc2 kinase. J Biol Chem 276: 6456-6463, 2001.
57. Xue XJ and Yuan XB: Nestin is essential for mitogen-stimulated proliferation of neural progenitor cells. Mol Cell Neurosci 45: 26-36, 2010.

58. Nakamura K, Taguchi E, Miura T, Yamamoto A, Takahashi K, Bichat F, Guilbaud N, Hasegawa K, Kubo K, Fujiwara Y, Suzuki R, Kubo K, Shibuya M and Isae T: KRN951, a highly potent inhibitor of vascular endothelial growth factor receptor tyrosine kinases, has antitumor activities and affects functional vascular properties. Cancer Res 66: 9134-9142, 2006.

59. Matsuda Y, Naito Z, Kawahara K, Nakazawa N, Korc M and Ishiwata T: Nestin is a novel target for suppressing pancreatic cancer cell migration, invasion and metastatis. Cancer Biol Ther 11: 512-523, 2011. 